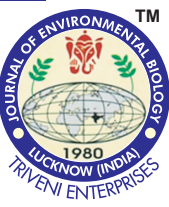

\title{
Induced genetic variations in Cuminum cyminum through supplemental UV-B radiation
}

\begin{tabular}{lll}
\hline Paper received: 01.06.2018 & Revised received: 28.09.2018 Re-revised received: $12.11 .2018 \quad$ Accepted: 14.12 .2018 \\
\hline
\end{tabular}

\section{Authors Info \\ G. Kumar and M. Bhardwaj* \\ Plant Genetics Laboratory, \\ Department of Botany, \\ University of Allahabad, \\ Prayagraj-211 002, India}

*Corresponding Author Email : mohinibhardwaj2811@gmail.com

\section{Edited by \\ Dr. Raghunath Sadhukar}

\section{Reviewed by}

Dr. Akarsh Parihar

Dr. Shailesh Tiwari

\section{Abstract}

Aim : The present study was conducted to investigate the genotoxic effect of UV-B radiation on morphological, biochemical and cytological parameters of Cuminum cyminum.

Methodology : The germinated roots of cumin were exposed to UV-B radiation at different intervals viz., 20 $\min 40 \mathrm{~min}$ and $60 \mathrm{~min}$, respectively, and some treated seeds were sown on pots for morphological and biochemical observation.

Results : Chromosomal studies divulged that UV-B radiation has substantial impact on Active Mitotic Index (AMI \%). On increasing UV-B radiation dose, the chromosomal aberration rate elevated, thus AMI \% moderately decreased and Total Abnormality percentage (TAB \%) gradually increased. Different types of chromosomal abnormalities were ascertained, among which scattering was more prominent. The morphological observation showed that survival percentage and plant height decreased at elevated dose of UV-B. Biochemical results indicated that chlorophyll a, chlorophyll b and carotenoid contents decreased as compared to control, but proline content showed significant increment athigher doses of UV-B.

Interpretation : The observation elucidates that UV-B causes chromosomal aberrations during cell

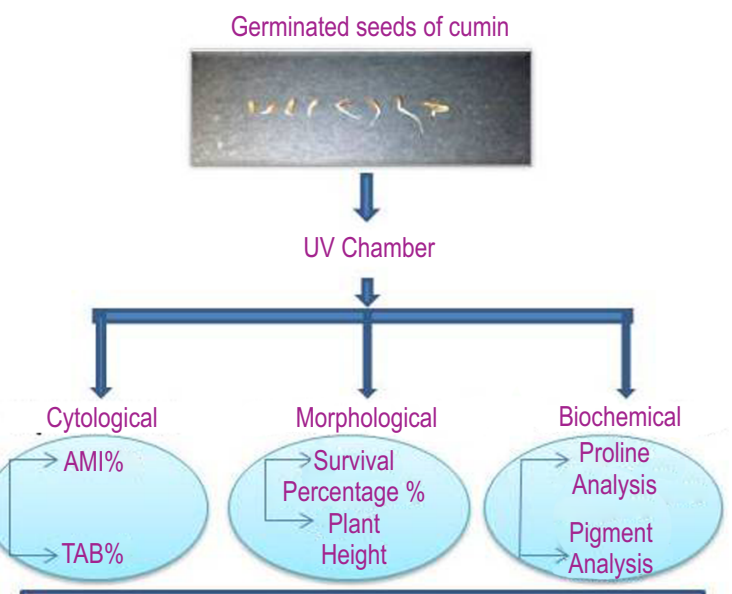

AMI percentage decreases and TAB percentage increases on increment of UV doses. Enormous decline was observed in survival, plant height and chloropyll pigments whils proline content enhanced at higher doses of UV rays.

division and acts as a potent genotoxic agents for roots. Thus, it can be concluded from the above experiment that UV-B rays promote plant growth at low doses but at the higher doses, it subsequently hinders plant growth by damaging important constituents of plant cell.

Key words: Active mitotic index, Chromosomal abnormality, Cuminum cyminum, Total abnormality percentage, UV-B rays

How to cite : Kumar, G. and M. Bhardwaj : Induced genetic variations in Cuminum cyminum L. through supplemental UV-B radiation.. J. Environ. Biol., 40, 342346 (2019). 


\section{Introduction}

Earth incorporates both ionizing and non-ionizing radiations. All living and non living organisms are inevitably exposed to these types of radiation. Ultra-violet rays are part of electromagnetic spectrum. Ultra-violet radiation is enhanced due to dissolution of protective ozone layer. Among three types of UV rays (UV-A, UV-B, UV-C), UV-B light $(280-315 \mathrm{~nm})$ is a natural component of sunlight, and due to its short wavelength, it has the highest energy of sunlight spectrum at the Earth's surface (Jansen et al., 1998). Exposure of UV-B is increasing due to depletion of ozone layer linked to chlorofluorocarbons and breaking of $\mathrm{O}_{3}$ structure by chlorine (Rowland, 2006).In plants, wide inter- and intraspecific differences have been reported in response to UV-B irradiation with respect to growth, production of dry matter and biochemical changes (Milchunas et al., 2004). Different species have different responses to the level of UV-B irradiation (Frohnmeyer et al., 2003).

Strong absorption of UV-B photons by biologically important macromolecules i.e., proteins and nucleic acids has a large effect on plant and animals metabolisms (Caldwell et al., 2007; Heisler et al., 2003). The effects of frequent UV exposure on plants are reduced growth, photosynthetic activity and flowering (Teramura et al., 1991; Santos et al., 2004; Jansen and Bornman, 2012). Growth parameters like plant height and leaf area are significantly reduced in wheat, rice, maize, rye, soybean, sunflower, cucumber and spinach under high UV-B radiation (Chatterji, 2015; Mishra et al., 2014). Ultraviolet-C and B influences DNA through the production of cyclobutane pyrimidine dimers leading to mutations (McLennan, 1987).

Information on the action of UV-B radiation as well as of endogenous or exogenous antioxidant on the meristematic cells is very limited (Perennes et al., 1999; Potters et al., 2000). Cumin is an important spice crop of India, belonging to family Apiaceae. Cumin plant showed wide range of pharmacological activities including antimicrobial, antioxidant, anticancer, hypolipidemic, cardiovascular, central nervous, respiratory, immunological, antiinflammatory, analgesic antipyretic and many other pharmacological effects (Al-Snafi, 2016). Reason behind preference of meristematic root tips for study is that treatments can be carried out in dark to avoid photoreactivation and due to low photolyase activity; root tips are prone to UV-B radiation. In view of the above, the present study was carried out to determine the exogenous effects of UV-B rays on root meristems of Cuminum cyminum.

\section{Materials and Methods}

Plant Material: Healthy Cumin seeds of variety GC 4 (Gujarat Cumin 4) were procured from Seed Spices Research Station S.D. Agriculture University, Jagudan Gujarat.

UV-B treatment: Seeds were surface sterilized in sodium hypochlorite for 10 min followed by washing with distilled water.
Presoaked cumin seeds were allowed to germinate at $25^{\circ} \mathrm{C}$ in an incubator. Fully germinated cumin seeds of uniform size root tips were selected. Petriplates containing germinated seeds were placed inside UV chamber. One petriplate out of three was removed from UV chamber after $20 \mathrm{~min}$, and subsequently other two were removed after 40,60 min after which petriplates were left undisturbed for one hour for recovery. After treatment some germinated seeds were sown in pots and some were used for cytological study.

Cytological analysis: Irradiated roots were fixed in Carnoy's fixative along with control sets. After $24 \mathrm{hrs}$, roots were preserved in $90 \%$ alcohol. UV-B irradiated roots were hydrolyzed in $1 \mathrm{~N} \mathrm{HCl}$ and then washed under running water to remove additional chemical and dried on blotting paper. Roots were stained using $2 \%$ acetocarmine, slides were prepared by squash technique and the photographs were taken under PCTV Vision Photography Software. Experiment was performed in three replicates along with control. Active Mitotic Index was calculated according to Edgar (1961) and Balog (1982). The morphological parameters were recorded, the survival percentage was taken after 21 days from sowing and plant height was taken after 45 days in centimeters.

Biochemical analysis: Photosynthetic pigments were analyzed by preparing leaf extract using $80 \%$ acetone and optical density of supernatant was taken at three different wavelengths $(470 \mathrm{~nm}$, $646 \mathrm{~nm}$ and $663 \mathrm{~nm}$ ) following the procedure of Lichtenthaler and Wellburn (1983). Chlorophyll $a$, Chlorophyll $b$ and Carotenoids contents were computed there upon. The proline content was quantified according to Bates et al. (1973).

Statistical analyses: Data was analyzed using SPSS 16.0 software. One way analysis of variance (ANOVA) and Duncan's Multiple Range Test $(p \leq 0.05)$ was performed and the graph was plotted by using Sigma plot 10.0 software.

\section{Results and Discussion}

Cytological studies of UV-B treated cumin seeds produced toxic effect on chromosomes. With respective increase in UV-B exposure on root meristems, AMI percentage decreased, while TAB \% increased. Thus, AMI and TAB percentage showed inverse relationship with each other in UV-B treated sets. Highest AMI \% was recorded in control sets $11.49 \pm 0.18^{\mathrm{a}}$ which was reduced to $7.75 \pm 0.44^{\circ}$ at UV 60 min dose while the lowest TAB $\%$ was observed at UV 20 min dose i.e. $1.85 \pm 0.04$, which show elevation up to $6.93 \pm 0.20$ in UV-60 min sets (Table 1). Reduced $\mathrm{AMI} \%$ may be due to inhibition of DNA synthesis at $S$ phase that probably occurred due to decrease in ATP level and due to the pressure from the functioning of the energy production centre (Sudhakar et al., 2001). In-depth cytogenetic study of chromosomal morphology in case of control revealed that chromosome complement was $2 n=14$ as seen at equatorial plate in metaphase and 14:14 poleward migration was recorded at anaphase (Fig.1A, B). Various chromosomal anomalies viz., 
scattering, stickiness, precocious movement of chromosome, unorientation, laggard etc were detected at both metaphasic and anaphasic stages in treated sets (Fig.1). The most dominant chromosome abnormality observed was scattering which may be due to the loss of microtubules of spindles fibers, unequal separation whereas unorientation of chromosomes may be attributed to disturbance in spindle formation. (Fig.1C, J). Fig. 2a and $2 \mathrm{~b}$ indicates graphical representation of metaphasic and anaphasic abnormalities which progressively increased along with exposure of UV-B radiation. Regular mitotic division was disturbed at higher doses of UV-B radiation resulting in Cmetaphase and loop formation at metaphase. According to Levan (1938), C metaphase is caused due to inactivation of spindle fibres, followed by a random scattering of chromosomes over the cell. (Fig.1D). Looping of chromosome is mainly due to abnormal function of spindle which fails to attach with kinetochore resulting in improper chromosomal division. (Fig.1E). Unorientation (Fig.1F, K) may occur due to disruption of spindle structure or function as per UV-B radiation, leading to imbalance of spindle fibre on both the sides of centromere traction power or chromosome acentric fracture cannot cause normal movement of chromosome (Han et al., 2007).

Chromosome stickiness leads to inactivation of DNA replication, increased chromosomal contraction and condensation or nucleoproteins probably leading to cell death (Khanna and Sharma, 2013). (Fig.1G, H). Precocious movement of chromosomes observed at metaphase might be formed due to early chiasma terminalisation or univalent chromosome formation at the end of prophase (Kumar and Rai, 2007). Laggard chromosome may depend on the moving speed and process of an individual chromosomes differing from normal ones (Qian, 2004) (Fig.1I). According to Liu et al. (2015), the chromosome bridge may result due to enhanced activity of UV-B radiation, making chromosome breaks, and then the two chromosome sides are respectively healed, producing with double centromere chromosomesi.e., "chromosome bridges" (Fig.1L).

At low doses of UV-B treatment, plants were able to recover from harmful effects of UV-B rays by various means of DNA replication and DNA repair. But in case of higher dose, UV$B$ radiation breaks down the plant self-protection system and inhibits the action of cell DNA replication transcription and protein synthesis (Liu et al., 2015). DNA damage induced by UV-B radiations might have influenced the expression of number of genes leading to alterations in proteins that control many metabolic processes like plant development, cell cycle (Abdel Haliem et al., 2013). UV-B radiation can make cell DNA base mutate and induce pyrimidine dimer. Once dimers are formed in DNA, double chain of hydrogen bonds are damaged, and the normal DNA replication would not be performed. This could create chromosomal mutations which occur during cell division (Barnes et al., 1990). UV-B treated sets were morphologically analyzed on survival percentage and plant height parameters. The survival percentage and plant height of cumin plants decreased with increased exposure of UV-B radiation. Lowest survival percentage was recorded in UV-60 min i.e., $49.0 \pm 2.30^{\mathrm{d}}$ followed by $68.6 \pm 2.02^{\mathrm{c}}$ in UV- 40 and $86.0 \pm 1.15^{\mathrm{b}}$ in UV-20 min whereas highest percentage was $95.0 \pm 0.57^{\mathrm{a}}$ in control sets (Fig. 3a). Maximum height was observed in control i.e., $25.59 \pm 1.57^{\mathrm{a}}$ followed by $21.85 \pm 1.34^{\mathrm{a}}, 15.78 \pm 0.68^{\mathrm{b}}$, $9.61 \pm 1.03^{\mathrm{c}}$ in UV 20,40 and $60 \mathrm{~min}$. respectively (Fig. 3b).

UV-B rays causes reduction in survivability at higher dose of UV-B radiation which makes root growth shorter and bender. The growth of plant is reduced in response to UV-B treatment. This reduction is associated with UV-dependent destruction of the growth regulator indole-3-acetic acid (IAA) and formation of growth-inhibiting IAA photoproducts. Reduction in growth could be associated with UV-B induced inhibition in photosynthetic rate and destruction of growth promoting hormone indole acetic acid (IAA) (Kulandaivelu et al., 1989). It was reported that UV radiation increases ethylene production and that this hormone decreases stem elongation and increases stem thickness (Ros and Tevini, 1995).

Biochemical analysis comprises of photosynthetic pigments quantification and proline estimation. Chlorophyll a, Chlorophyll b and Carotenoid contents were measured in UV-B treated sets. Chl a reduced from $4.24 \pm 0.06^{\mathrm{a}}\left(\mu \mathrm{g} \mathrm{ml}{ }^{-1} \mathrm{f}\right.$. wt.) in control sets to $3.64 \pm 0.37^{b}$ ( $\mu \mathrm{g} \mathrm{ml}^{-1} \mathrm{f}$. wt.) in UV $20 \mathrm{~min}, 3.23 \pm 0.04^{\mathrm{c}}$ ( $\mu \mathrm{g} \mathrm{ml}^{-1}$ f. wt.) in UV $40 \mathrm{~min}, 2.23 \pm 0.05^{\mathrm{d}}$ ( $\mu \mathrm{g} \mathrm{ml}^{-1} \mathrm{f}$. wt.) in UV 60 min. Chl b decreased from $2.89 \pm 0.31 \mathrm{a}\left(\mu \mathrm{g} \mathrm{ml} \mathrm{l}^{-1} \mathrm{f}\right.$. wt.) in control to $2.63 \pm 0.27^{\mathrm{a}}, 2.35 \pm 0.10^{\mathrm{a}}, 1.35 \pm 0.13^{\mathrm{b}}$ ( $\mu \mathrm{g} \mathrm{ml}^{-1} \mathrm{f}$. wt.) in UV 20, 40, $60 \mathrm{~min}$, respectively. Highest carotenoid content was recorded $1.92 \pm 0.14^{\mathrm{a}}$ ( $\mu \mathrm{g} \mathrm{ml}^{-1} \mathrm{f}$. wt.) in control while $1.56 \pm 0.06^{\mathrm{a}}, 1.48 \pm 0.21^{\mathrm{a}}$, $0.73 \pm 0.16^{\mathrm{b}}$ ( $\mu \mathrm{g} \mathrm{ml}^{-1} \mathrm{f}$. wt.) in UV-20, 40, $60 \mathrm{~min}$, respectively (Fig.3c). The contents of chlorophyll $a, b$ and total chlorophyll decreases when compared with control values with increasing UV-radiation levels (Salama et al., 2011). Chl a, Chl b and carotenoids are the major light harvesting pigments of photosynthesis and they are involved in synthesis of metabolites that promote the plant growth and development. However, increase in UV radiation damages the chloroplast which causes detrimental effects in various photosynthetic pigments. It has been reported that the concentration of $\mathrm{Chl} a$ and $\mathrm{Chl} \mathrm{b}$ significantly decreased in Barleria obtuse and Vigna unguiculata plants that were exposed to UV radiation (Musil et al., 2002). Thus, chlorophyll content can be studied as one of the markers of cellular stress, and its decreased level can provide the evidence of severity of stress in plants (Ashraf and Harris, 2004).

Biosynthesis of carotenoids occur in cellular plastids where they are associated with light harvesting complexes (Kopsell and Kopsell , 2006). Therefore, carotenoid contents may be reduced due to damage caused by UV-B rays on light harvesting complexes. These compounds absorb UV-B before reaching to UV sensitive targets like chloroplast and other organelles, thus acting as solar shield. But when UV-B dose increases over threshold level such substances are unable to screen UV damage, and decrease in chlorophyll pigments indicated the damage of chloroplast caused by UV radiation. 


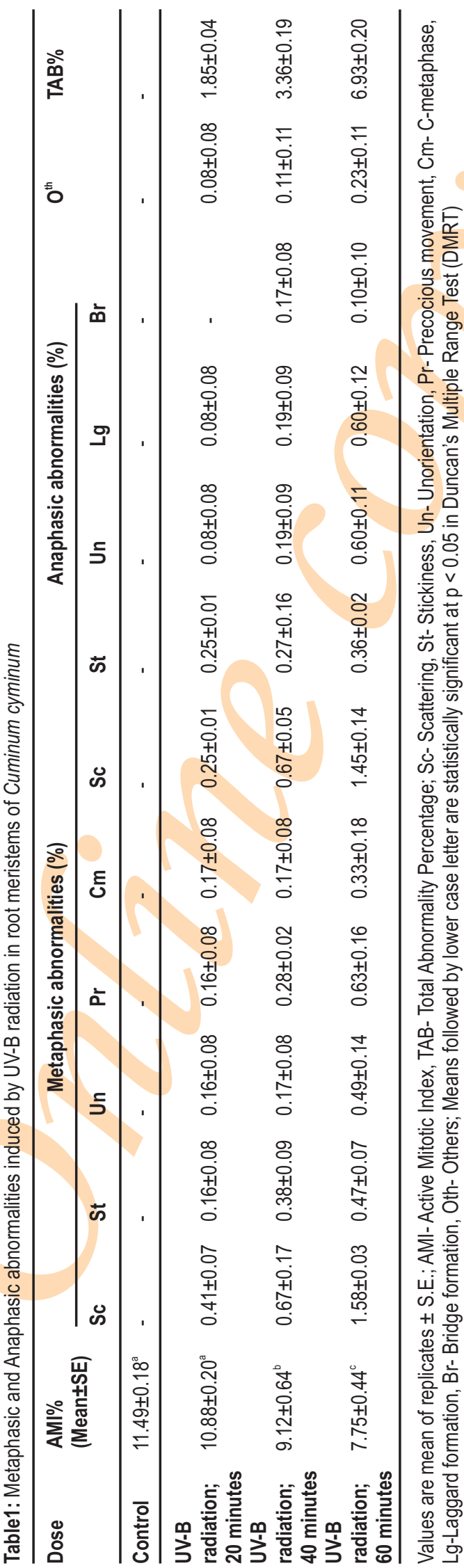

* Journal of Environmental Biology, May 2019 \% 




A
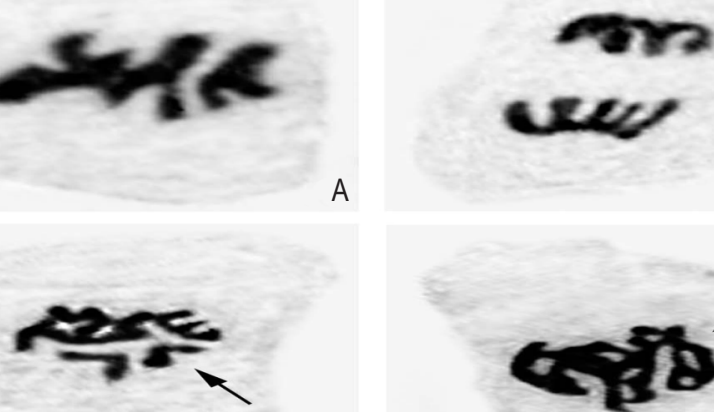

D

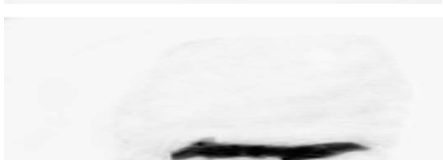

G

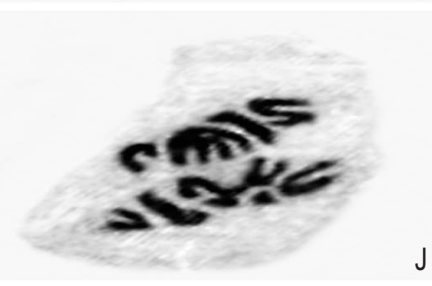

B

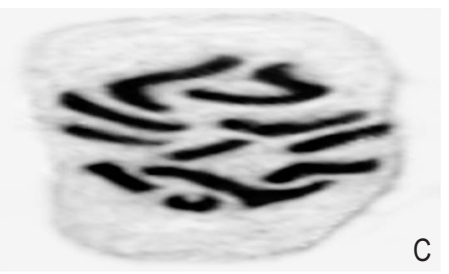

E

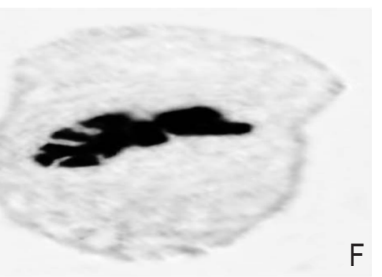


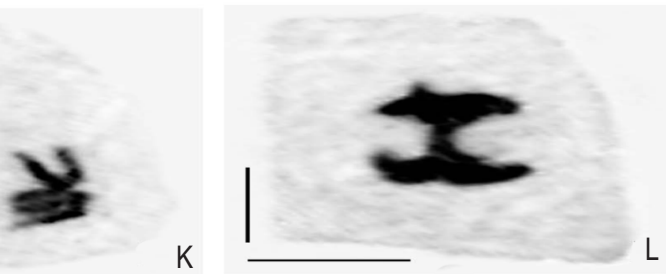

Fig. 1: UV-B induced chromosomal aberrations at mitotic stage. A. Normal metaphase (2n=14), B. Normal anaphase (14:14), C. Scattering at metaphase, D. C-metaphase, E. Loop formation, F. Unorientation at metaphase, G. Stickiness at metaphase, H. Stickiness at anaphase, I. 2 Laggards chromosome with one forward chromosome at anaphase, J. Unorientation with Scattering at anaphase, K. Unorientation at anaphase, L. Bridge formation [SCALEBAR $=10 \mu \mathrm{m}$ ].



(a)

(b)

Fig. 2: UV-B induced metaphasic abnormalities (a) and anaphasic abnormalities (b) in root meristems of Cuminum cyminum. 
Proline content of control sets was recorded to be $0.28 \pm 0.04^{\mathrm{d}}$ $\mu \mathrm{mol} \mathrm{g}{ }^{-1} \mathrm{f}$. wt., it elevated upto $1.47 \pm 0.13 \mathrm{c} \mu \mathrm{mol} \mathrm{g}{ }^{-1} \mathrm{f}$. wt. in UV-20 min, $3.20 \pm 0.10^{b} \mu \mathrm{mol} \mathrm{g}^{-1} \mathrm{f}$. wt. in UV-40 min and $3.97 \pm 0.07 \mathrm{a} \mu \mathrm{mol}$ $\mathrm{g}^{-1} \mathrm{f}$. wt. in UV-60 min treated sets (Fig. 3d).

Proline is a stress marker and play a critical role in protecting plants under stress. On increasing the duration of UV-B exposure proline content in plants is elevated to cope itself from the damages caused by radiation. Proline provides less than $5 \%$ of the total pool of free amino acids in plants under stress free condition; whereas the concentration increased up to $80 \%$ during stress (Matysik et al., 2002). According to Salama et al. (2011) increasing proline content is referred to as protective mechanism due to the generation of reactive oxygen species by UV radiation. Therefore, it can be concluded from present investigation that when plant exposed to UV -B rays for longer duration, adversely affect the plant growth while lower dose i.e., 20 min shows high $\mathrm{AMI} \%$ and low $\mathrm{TAB} \%$ chromosomal aberrations and very slight changes were observed morphologically and biochemically at lower dose as compared to control plants which may be significantly utilized by plant to adapt changing environmental conditions. Further studies can be done at meiotic level for the establishment of some beneficial high yielding traits in cumin through mutation breeding so that this economically and medicinally important crop might be able to withstand hazards of $U V-B$ radiation in the coming years.

\section{Acknowledgments}

The authors acknowledge Sardarkrushinagar Dantiwada Agricultural University (S.D.A.U) Jagudan, Gujarat for supplying pure inbred seeds of cumin. Authors also thank the members of (a)

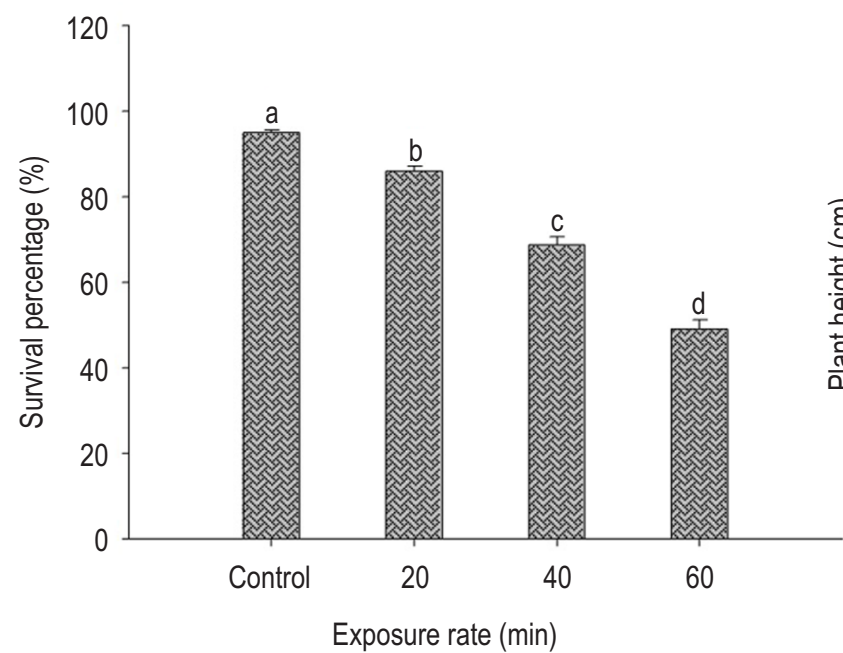

UV-B

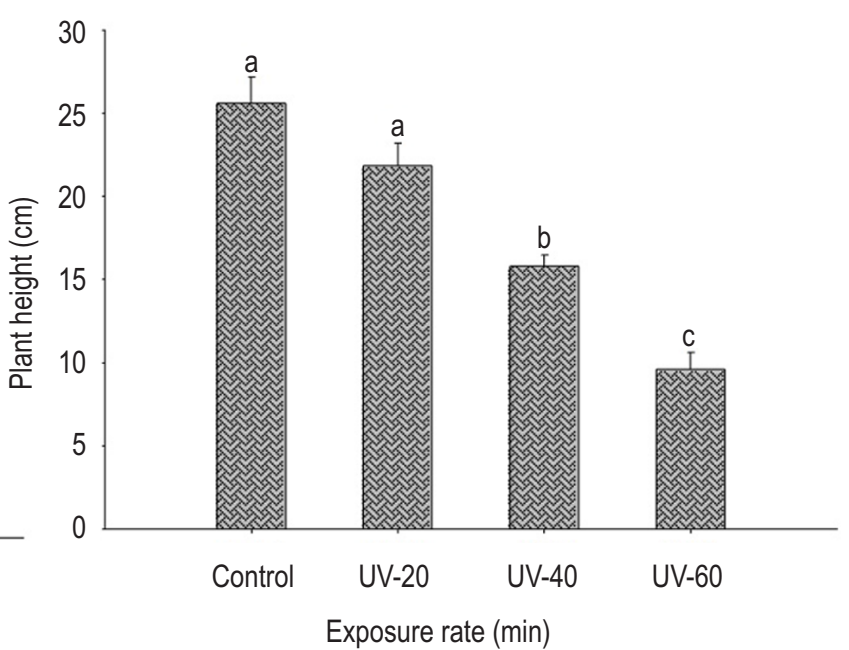

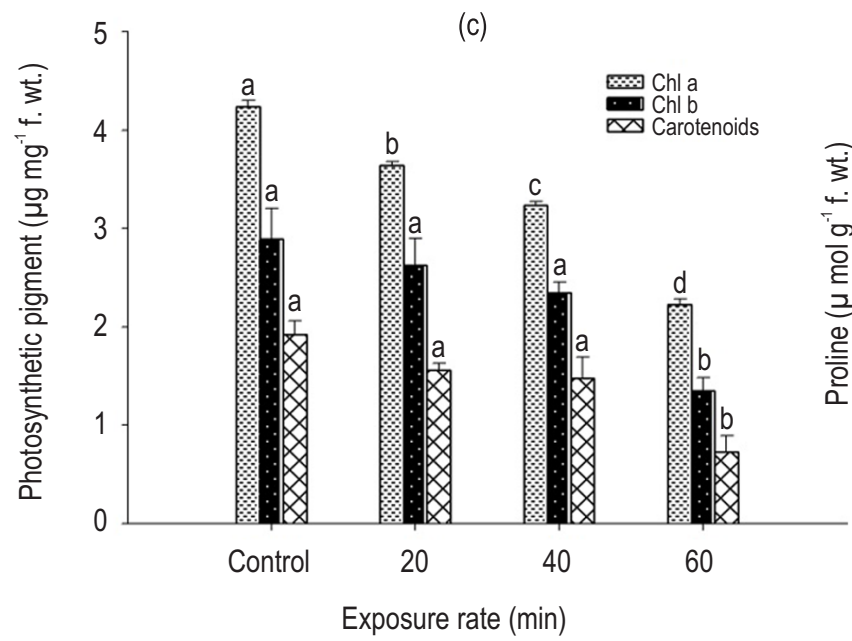

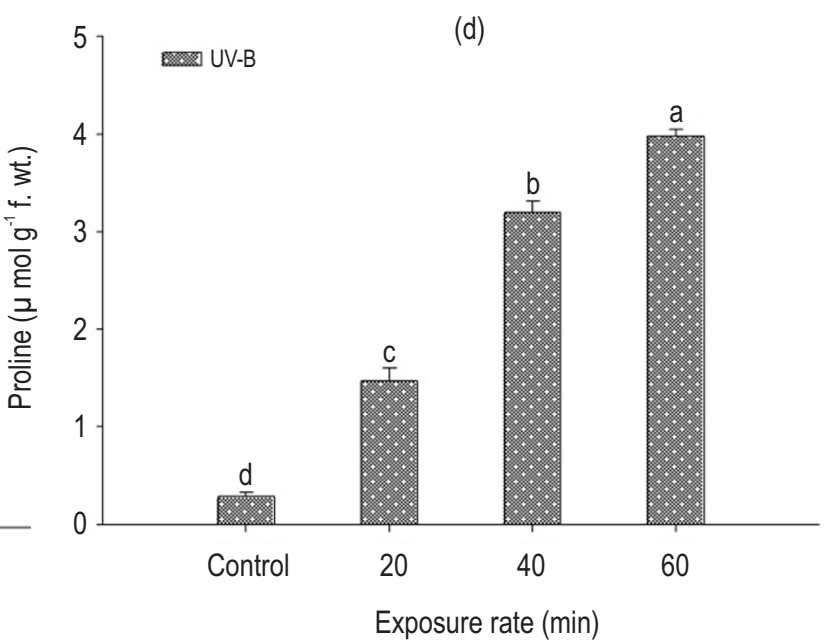

Fig. 3: Effect of UV-B radiation on Cuminum cyminum (a) Survival percentage, (b) Plant height, (c) Photosynthetic pigments and (d) Proline content. 
Naithani Plant Genetics Laboratory and the Head of the Department for their valuable support.

\section{References}

Abdel Haliem, E., H. Abdullah and A.A. AL-Huqail: Oxidative damage and mutagenic potency of fast neutron and UV-B radiation in pollen mother cells and seed yield of Vicia faba L. Bio. Med. Res. Int. 2013, Article ID 824656 (2013).

Al-Snafi, A.E.: The pharmacological activities of Cuminum cyminum-A review. IOSR J. Pharm., 6, 46-65 (2016).

Ashraf, M.P.J.C. and P.J.C. Harris: Potential biochemical indicators of salinity tolerance in plants. Plant Science, 166, 3-16 (2004).

Balog, C.: The mitotic index in diploid and triploid in Allium roots. Cytologia, 47, 689-697 (1982)

Barnes, P.W., S.D. Flint and M.M. Caldwell: Morphological responses of crop and weed species of different growth forms to ultraviolet-B radiation. Amer. J. Bot., 77, 1354-1360 (1990).

Bates, L.S., R.P. Waldren and I.D. Teare: Rapid determination of free proline for water-stress studies. Plant and Soil, 39, 205-207 (1973)

Caldwell, M.M., J.F. Bornman, C.L. Ballaré, S.D. Flint and G. Kulandaivelu: Terrestrial ecosystems, increased solar ultraviolet radiation, and interactions with other climate change factors. Photochemi. Photobiol. Sci., 6, 252-266 (2007).

Chatterji, A.: Impact of UV-B radiations on morphology of Ocimum and Mentha (Family-Lamiaceae) by ascorbic acid. IJAR, 1, 347-351 (2015).

Edgar, E.: Fluctuations in mitotic index in the shoot apex of Lonicera nitida. University of Canterbury, Christchurch, New Zealand (1961).

Frohnmeyer, $H$. and D. Staiger: Ultraviolet-B radiation-mediated responses in plants. Balancing damage and protection. Plant Physiology, 133,1420-1428 (2003).

Han, R., Y.F. Zheng and C.H. Wang: Effects of enhanced UV-B radiation on the growth of aerial parts and root of maize. Ecol. Environ., 2 323-326 (2007).

Heisler, G.M., R.H. Grant, W. Gao and J.R. Slusser: Ultraviolet radiation and its impacts on agriculture and forests. Agricult. Forest Meteorol., 120,120-133 (2003).

Jansen, M.A. and J.F. Bornman: UV-B radiation: From generic stressor to specific regulator. Physiologia Plantarum, 145, 501-504 (2012).

Jansen, M.A., V. Gaba and B.M. Greenberg: Higher plants and UV-B radiation: Balancing damage, repair and acclimation. Trends in Plant Sci., 3,131-135 (1998).

Khanna, N. and S. Sharma: Allium cepa root chromosomal aberration assay: Areview. Ind. J. Pharma. Biol. Res., 1, 105-119 (2013).

Kopsell, D.A. and D.E. Kopsell: Accumulation and bioavailability of dietary carotenoids in vegetable crops. Trends Plant Sci., 11, 1360-1385 (2006).

Kulandaivelu, G., S. Maragatham and N. Nedunchezhian: On the possible control of ultraviolet-B induced response in growth and photosynthetic activities in higher plants. Physiologia Plantarum, 76, 398-404 (1989)
Kumar, G. and P.K. Rai: EMS induced karyomorphological variations in maize (Zea mays L.) inbreds. Turkish J. Biol., 31,187-195 (2007).

Levan, A.: The effect of colchicine on root mitoses in Allium. Hereditas, 24, 471-486 (1938)

Lichtenthaler, H.K. and A.R. Wellburn: Determinations of total carotenoids and chlorophylls $a$ and $b$ of leaf extracts in different solvents. Biochem. Soc. Trans.,11, 591-592 (1983).

Liu, F., H. Chen and R. Han: Different doses of the enhanced UV-B radiation effects on wheat somatic cell division. Cell Bio., 4, 30 (2015)

Matysik, J., Alia, B. Bhalu and P. Mohanty: Molecular mechanisms of quenching of reactive oxygen species by proline under stress in plants. Curr. Sci., 82, 525-532 (2002).

McLennan, A.G.: The repair of ultraviolet light-induced DNA damage in plant cells. Muta. Res./Fundam. Molec. Mechani. Mutagen., 181, 1-7 (1987)

Milchunas, D.G., J.Y. King, A.R. Mosier, J.C. Moore, J.A. Morgan, M.H. Quirk and J.R. Slusser: UV radiation effects on plant growth and forage quality in a shortgrass steppe ecosystem. Photochemistry and Photobiology, 79, 404-410 (2004).

Mishra, S., T.K. Nailwal and S.B. Agrawal: Study on individual and interactive effects of supplemental UV-B radiation and heavy metals on Spinacea oleracea. J. Env. Biol., 35, 333 (2014)

Musil, C.F., S.B. Chimphango and F.D. Dakora: Effects of elevated Ultraviolet-B radiation on native and cultivated plants of Southern Africa. Annals of Botany, 90,127-137 (2002).

Perennes, C., N. Glab, B. Guglieni, M.P. Doutriaux, T.H. Phan, S. Planchais and $\mathrm{C}$. Bergounioux: Is arcA3 a possible mediator in the signal transduction pathway during agonist cell cycle arrest by salicylic acid and UV irradiation? J. Cell Sci., 112,1181-1190 (1999).

Potters, G., N. Horemans, R.J. Caubergs and H. Asard: Ascorbate and dehydroascorbate influence cell cycle progression in a tobacco cell suspension. Plant Physiol., 124,17-20 (2000).

Qian, X. W.: Mutagenic effects of chromium trioxide on root tip cells of Vicia faba. J. Zhejiang Univ. Sci., 5,1570-1576 (2004).

Ros, J. and M. Tevini: Interaction of UV-radiation and IAAduring growth of seedlings and hypocotyl segments of sunflower. J. Plant Physiol., 146, 295-302 (1995).

Rowland, F. S.: Stratospheric ozone depletion. Philosophical Transactions of the Royal Society B: Biological Sciences, 361, 769-790 (2006).

Salama, H.M., A.A. Al Watban and A.T. Al-Fughom: Effect of ultraviolet radiation on chlorophyll, carotenoid, protein and proline contents of some annual desert plants. Saudi J. Biol. Sci., 18, 79-86 (2011).

Santos, I., F. Fidalgo, J.M. Almeida and R. Salema: Biochemical and ultrastructural changes in leaves of potato plants grown under supplementary UV-B radiation. Plant Sci., 167, 925-935 (2004).

Sudhakar, R., K. N. Ninge Gowda and G. Venu: Mitotic abnormalities induced by silk dyeing industry effluents in the cells of Allium cepa L. Cytologia, 66, 235-239 (2001).

Teramura, A.H., L.H. Ziska and A. Sztein: Changes in growth and photosynthetic capacity of rice with increased UV-B radiation. Physiol. Plant., 83, 373-380 (1991). 